\title{
Adolescent Changes in Hindbrain Noradrenergic A2 Neurons in Male Rats
}

Laurie Pham, Madelyn R. Baker, Ziasmin Shahanoor, and Russell D. Romeo ${ }^{1 *}$

${ }^{1}$ Department of Psychology and Neuroscience and Behavior Program Barnard College of Columbia University

New York, NY 10027

\section{*Correspondence to:}

Russell D. Romeo, Ph.D.

Department of Psychology and Neuroscience and Behavior Program

Barnard College of Columbia University

New York, NY 10027

Tel: (212)854-5903

Fax: (212)280-8799

Email: rromeo@barnard.edu

Short Title: Adolescent Changes in A2 Neurons 


\section{ABSTRACT}

During adolescence, the increased susceptibility to stress-related dysfunctions (e.g., anxiety, drug use, obesity) may be influenced by changes in the hormonal stress response mediated by the hypothalamic-pituitary-adrenal (HPA) axis. We have previously reported that restraint stress leads to significantly prolonged HPA responses in pre-adolescent compared to adult rats. Further, pre-adolescent animals exposed to restraint show greater levels of neural activation than adults in the paraventricular nucleus of the hypothalamus (PVN), a key nucleus integrating information from brain regions that coordinate HPA responses. Here, we examined the potential contribution of the noradrenergic A2 region of the nucleus of the solitary tract (NST) as a contributor to these age-dependent shifts in HPA reactivity. Specifically, we used double-labeled immunohistochemistry for FOS and dopamine$\beta$-hydroxylase $(\mathrm{D} \beta \mathrm{H})$ to measure cellular activation and noradrenergic cells, respectively, before or after restraint stress in pre-adolescent (30 days old) and adult (70 days old) male rats. We also measured the density of $\mathrm{D} \beta \mathrm{H}$-immunoreactive fibers in the PVN as an index of noradrenergic inputs to this area. We found that preadolescent animals have a greater number of $\mathrm{D} \beta \mathrm{H}$-positive cells in the $\mathrm{A} 2$ region compared to adults, yet the number and percentage of double-labeled $\mathrm{D} \beta \mathrm{H} / \mathrm{FOS}$ cells were similar between these two ages. We found no differences between the ages in the staining intensity of $\mathrm{D} \beta \mathrm{H}$-immunoreactive fibers in the PVN. These data indicate there are adolescent-related changes in the number of noradrenergic cells in the A2 region, but no clear association between the increased stress reactivity prior to pubertal maturation and activation of A2 noradrenergic afferents to the PVN. 
Adolescent Changes in A2 Neurons, Page 3

Keywords: adolescence, dopamine-beta-hydroxylase, nucleus of the solitary tract, puberty, restraint stress 


\section{Introduction}

Adolescent development is marked by significant changes in hypothalamicpituitary-adrenal (HPA) axis stress-induced hormonal reactivity in both human and non-human animals (Dahl and Gunnar, 2009; Hostinar and Gunnar, 2013; McCormick and Mathews, 2007; McCormick et al., 2010; Romeo, 2010a; Romeo, 2010b; Romeo, 2013). For instance, stressors with both physiological and psychological components, such as restraint (Hall and Romeo, 2014; Minhas et al., 2016; Romeo et al., 2004a; Romeo et al., 2004b; Romeo et al., 2006b), hypoxia (Goldman et al., 1973; Vazquez and Akil, 1993), and intermittent foot shock (Goldman et al., 1973), result in prepubertal males and females exhibiting significantly greater and more prolonged adrenocorticotropic hormone (ACTH) and corticosterone responses compared to adults. Though the exact mechanisms that mediate this heightened hormonal reactivity prior to pubertal maturation are unclear, it appears that both peripheral and central factors play a role (Romeo et al., 2016). For example, the adrenal glands of prepubertal rats produce higher levels of corticosterone and display greater sensitivity to ACTH than those of adults (Foilb et al., 2011; Romeo et al., 2014). In the brain, the paraventricular nucleus of the hypothalamus (PVN) shows higher levels of neuronal activation following restraint stress in prepubertal compared to adult animals (Lui et al., 2012; Romeo et al., 2006a; Viau et al., 2005), particularly within the corticotropic-releasing hormone $(\mathrm{CRH})$-containing cells in the parvocellular region of the PVN (Romeo et al., 2006a). Importantly, it is this parvocellular portion of the PVN that is a critical integrator of 
information from limbic, hypothalamic, and brainstem regions that coordinates the HPA hormonal response (Herman et al., 2003; Ulrich-Lai and Herman, 2009).

Converging lines of research have drawn attention to the importance of the noradrenergic-containing A2 region of the nucleus of the solitary tract (NST) in HPAmediated hormonal responses following a variety of physical and/or psychological stressors (Kvetnanky et al., 2009; Rinaman, 2011). First, the A2 region sends direct noradrenergic afferent projections to the parvocellular PVN (Cunningham and Sawchenko, 1988; Cunningham et al., 1990; Sawchenko and Swanson, 1981; Sawchenko and Swanson, 1982). Second, acute stressors lead to increased neuronal activation, as indexed by FOS, in noradrenergic-containing cells in this region (Crane et al., 2005; Dayas et al., 2001a; Dayas et al., 2001b; Dayas et al., 2004; Pezzone et al., 1993). Finally, lesions of noradrenergic neurons in the A2 region significantly attenuate the rise of plasma corticosterone levels following restraint or ether inhalation stress (Bundzikova-Osacka et al., 2015; Gaillet et al., 1993). Though the A2 region of the NST is not the only direct afferent driving stressinduced HPA reactivity (Herman et al., 2003), these studies suggest that pubertal changes in NST function may in part mediate the differential PVN and hormonal responses observed in pre-adolescent and adult animals.

The purpose of the present experiment was to examine the number of singleand double-labeled dopamine-beta-hydroxylase (DßH)- and FOS-immunopositive cells in the A2 region of the NST in prepubertal and adult male rats before, immediately after, or 40 min following a 30 min session of restraint stress. $\mathrm{D} \beta \mathrm{H}$ and FOS were used as markers of norepinephrine-producing cells and neural activation, 
respectively. An additional goal of this experiment was to assess the staining intensity of $\mathrm{D} \beta \mathrm{H}$-immunopositive fibers in the parvocellular PVN as an index of potential age- and stress-dependent changes in noradrenergic innervation to this region. This semi-quantitative method has been used previously to measure alterations in the amount of noradrenergic input to the PVN following noradrenergicspecific lesions of the A2 region of the NST (Bundzikova-Osacka et al., 2015). Based on the positive relationship between stress-induced activity of the NST and the HPA-mediated hormonal response, we hypothesized that pre-adolescent males would show greater numbers of double-labeled $\mathrm{D} \beta \mathrm{H}$ - and FOS-positive cells than adults in the A2 region of the NST following restraint stress. Furthermore, we hypothesized that pre-adolescent males would have higher levels of $\mathrm{D} \beta \mathrm{H}$ immunoreactive fiber densities in the PVN compared to adults.

\section{Results}

\subsection{Experiment 1: $D \beta H$ - and FOS-positive cells in the A2 Region of the NST}

A two-way ANOVA revealed a significant main effect of age on the number of $\mathrm{D} \beta \mathrm{H}$-positive cells in the $\mathrm{A} 2$ region $(\mathrm{F}(1,38)=14.07, P<0.05)$, with pre-adolescent animals showing a greater number of $\mathrm{D} \beta \mathrm{H}$-positive cells compared to adults, regardless of the stress time point (Figure 1A). There was no significant main effect of stress or interaction between age and stress on the number of single-labeled $\mathrm{D} \beta \mathrm{H}$ positive cells. A two-way ANOVA revealed a significant main effect of time on the number of FOS-immunoreactive cells in the A2 region $(\mathrm{F}(2,38)=4.03, P<0.05)$, such that pre-adolescent and adult animals show a greater number of FOS-positive 
cells 40 min after the termination of the 30 min restraint sessions (Figure 1B). There was no significant main effect of age or interaction between age and stress on the number of single-labeled FOS-positive cells. Finally, a two-way ANOVA revealed a main effect of time on both the number and percentage of $\mathrm{D} \beta \mathrm{H} / \mathrm{FOS}$ double-labeled cells in the A2 region $(F(2,38)=4.04$ and 3.07 , respectively, $P<0.05)$. More specifically, both pre-adolescent and adult animals had a greater number and percentage of $\mathrm{D} \beta \mathrm{H} / \mathrm{FOS}$ cells 40 min following the stressor than either before or immediately after the 30 min restraint stress session (Figure 1C and 1D). Figure $2 \mathrm{~A}$ and $B$ provide a representative photomicrograph of the single- and double-labeled $\mathrm{D} \beta \mathrm{H}$ and FOS-positive cells of the A2 region of the NST of a pre-adolescent male 40 min after the 30 min session of restraint stress had been terminated.

\subsection{Experiment 2: $D \beta H$ RODs in PVN}

For $\mathrm{D} \beta \mathrm{H}$ RODs in the parvocellular PVN, a two-way ANOVA showed a significant main effect of time $(F(2,38)=3.21, P<0.05)$ such that pre-adolescent and adult males 40 min after exposure to a 30 min session of restraint had higher $\mathrm{D} \beta \mathrm{H}$ immunoreactive RODs in the PVN compared to the pre-adolescent and adult males either before or immediately after termination of the restraint stress (Figure 3). Figure 4 A-D provides representative photomicrographs of the $\mathrm{D} \beta \mathrm{H}$ immunoreactivity in the PVN of a pre-adolescent male before or 40 min after the 30 min session of restraint stress had been terminated and the approximate areas that the immunoreactive RODs were measured (Figure 4). 


\section{Discussion}

These data describe an adolescent-related decrease in the number of $\mathrm{D} \beta \mathrm{H}$ containing cells in the A2 region of the NST. These data also show that despite preadolescent animals demonstrating significantly greater ACTH and corticosterone hormonal responses compared to adults after restraint stress (Hall and Romeo, 2014; Minhas et al., 2016; Romeo et al., 2004a; Romeo et al., 2004b; Romeo et al., 2006b), animals at both ages have similar levels of restraint-induced cellular activation in this noradrenergic cell group. Further, we report that pre-adolescent and adult males have similar levels of $\mathrm{D} \beta \mathrm{H}$ immunoreactivity in the parvocellular PVN, suggesting comparable noradrenergic inputs to the PVN before and after adolescence, a result consistent with a previously published report showing similar levels of noradrenergic innervation of the PVN in weanling and adult rats (Rinaman, 2001). Though these data collectively do not support our initial hypothesis of greater stress-induced noradrenergic activation in the NST prior to adolescence, these data do suggest adolescent-dependent changes in the A2 region of the NST.

The pubertal decrease in D $\beta \mathrm{H}$-positive cells in the NST was unexpected, and we are unclear what mechanism(s) may account for these age-related differences. It is possible that expression of $\mathrm{D} \beta \mathrm{H}$ decreases following pubertal maturation in the $\mathrm{A} 2$ region, and thus the detectability of the cells decreases as well. Additional experiments assessing potential pubertal changes in D $\beta H$ mRNA may shed on this possibility. The changes in the number of $\mathrm{D} \beta \mathrm{H}$-positive cells before and after pubertal development may be related to potential increases in cell death in this region of the NST during puberty. There are precedents in the literature for pubertal 
declines in cell proliferation in the male hippocampus (Ho et al., 2012) and decreases in the number of neurons in the amygdala and medial prefrontal cortex of male and female rats (Markham et al., 2007; Rubinow and Juraska, 2009; Willing and Juraska, 2015). Future experiments will need to further examine this pubertal-related difference in $\mathrm{D} \beta \mathrm{H}$-positive cell number in the $\mathrm{A} 2$ region and the processes responsible for the change.

The significant restraint stress-induced increase in the number of FOS singleand FOS/D $\beta \mathrm{H}$ doubled-labeled cells in the NST are in agreement with previously published experiments in adult rats (Crane et al., 2005; Dayas et al., 2001a; Dayas et al., 2001b; Dayas et al., 2004; Pezzone et al., 1993). However, the similar number and percentage of cells double-labeled with FOS and $\mathrm{D} \beta \mathrm{H}$ suggests little association between the prolonged stress-induced HPA response in prepubertal compared to adult animals and changes in noradrenergic activity in the NST afferents to the PVN. It is important to note that not all A2 noradrenergic neurons project to the PVN, and thus we may have missed a differential response within a more specific population of noradrenergic cells in this region. Studies using a combination of both $\mathrm{D} \beta \mathrm{H}$ and FOS labels in the NST with a retrograde tracer from the PVN, for instance, would help address this question.

A recent study utilized the intensity of $\mathrm{D} \beta \mathrm{H}$ immunoreactivity in the PVN as an index of the fiber density from noradrenergic NST afferents (Bundzikova-Osacka et al., 2015). In particular, Bundzikova-Osacka et al. reported that 6-hydroxydopamine (6-OHDA) lesion of the A2 region of the NST, which specifically targets the PVN projecting noradrenergic neurons, resulted in both a significant decrease in the 
number of $\mathrm{D} \beta \mathrm{H}$-positive cells in the $\mathrm{A} 2$ region as well as a significant decrease in $\mathrm{D} \beta \mathrm{H}$-immunoreactive fibers in the PVN (Bundzikova-Osacka et al., 2015). Though we did not find support for our hypothesis that pre-adolescent animals would have greater levels of $\mathrm{D} \beta \mathrm{H}$ staining in the PVN than adults, we did find that stress exposure in both pre-adolescent and adult animals resulted in higher $\mathrm{D} \beta \mathrm{H}$ densities in the PVN. This effect of stress on $\mathrm{D} \beta \mathrm{H}$ staining intensity is possibly due to stressinduced increases in $\mathrm{D} \beta \mathrm{H}$ expression in the $\mathrm{A} 2$ projection neurons, as has been noted previously in male rats (Mravec et al., 2015), and not stress-induced changes in the innervation of the PVN per se. Regardless, this change in $\mathrm{D} \beta \mathrm{H}$ staining is independent of the pubertal decrease in the number of $\mathrm{D} \beta \mathrm{H}$-positive cells in the $\mathrm{A} 2$ region of the NST reported here and the heightened stress-induced hormonal responses observed prior to puberty reported previously (Foilb et al., 2011; Goldman et al., 1973; Hall and Romeo, 2014; Minhas et al., 2016; Romeo et al., 2004a; Romeo et al., 2004b; Romeo et al., 2006b; Romeo et al., 2014; Vazquez and Akil, 1993).

Our data indicate that the increased hormonal stress reactivity exhibited by pre-adolescent animals following restraint stress is not associated with differences in neural activation of the $\mathrm{D} \beta \mathrm{H}$-containing cells in the A2 region of the NST. However, a substantial sub-population of neurons within this region also express vesicular glutamate transporters (Stornetta et al., 2002), a marker of glutamatergic cells, thus suggesting these neurons are co-releasing both norepinephrine and glutamate into the PVN upon stimulation. Given the known role of glutamate in activation of the 
PVN and the stress-induced hormonal response (Busnardo et al., 2013; Ziegler and Herman, 2000), it is possible that, with additional phenotyping of these cells, agedependent differences in neural activation patterns within the A2 region may emerge.

In conclusion, our data show pubertal decreases in the number of $\mathrm{D} \beta \mathrm{H}$ containing cells in the A2 region of the NST. Moreover, despite increased restraint stress-induced hormonal reactivity prior to puberty, the $\mathrm{D} \beta \mathrm{H}$-positive cells in the $\mathrm{A} 2$ region display similar levels of cellular activation following restraint stress in both preadolescent and adult male rats. These studies are the first steps in establishing the contribution of the NST, and other PVN afferents, in adolescent-related changes in HPA stress reactivity and the mechanisms through which these PVN afferents mediate this developmental shift in neuroendocrine function.

\section{Experimental Procedure}

\subsection{Animals and housing}

Male Sprague-Dawley rats were obtained from our breeding colony at Barnard College, weaned at 21 days of age, and housed two per cage in clear polycarbonate cages $(45 \times 25 \times 20 \mathrm{~cm})$ with wood chip bedding. All animals were maintained on a $12 \mathrm{~h}$ light-dark schedule (lights on at $0900 \mathrm{~h}$ ). All animals had ad libitum access to food and water and the animal room was maintained at $21 \pm 2^{\circ} \mathrm{C}$. All procedures were carried out in accordance with the guidelines established by the National Institutes of Health Guide for the Care and Use of Laboratory Animals and approved by the Institutional Animal Care and Use Committee (IACUC) of Columbia University. 


\subsection{Experimental design}

Two experiments were conducted. Experiment 1 measured the number and activation of noradrenergic cells in the A2 region of the NST using double-labeled immunohistochemistry for $\mathrm{D} \beta \mathrm{H}$ and FOS in pre-adolescent (30 days of age) and adult (70 days of age) male rats before and after a 30 min session of restraint stress. Experiment 2 examined $\mathrm{D} \beta \mathrm{H}$ immunohistochemical staining intensity in the parvocellular region of the PVN in the same cohort of animals used in Experiment 1.

To procure the brain tissue for these experiments, pre-adolescent and adult rats were weighed and transcardially perfused before (basal), immediately after the stressor (Time 0 ), or 40 min following termination of the stressor $(n=8$ per age and time point). These time points were chosen for analysis because of the differential stress-induced hormonal response exhibited during these post-stress time points and time for increases in FOS immunoreactivity to be detected (Foilb et al., 2011; Lui et al., 2012; Romeo et al., 2004a; Romeo et al., 2006a; Romeo et al., 2006b). For perfusions, animals were given an overdose of ketamine and xylazine (80 and 5 $\mathrm{mg} / \mathrm{kg}$, respectively) and perfused with $0.9 \%$ heparinized saline followed by $4 \%$ paraformaldehyde in $0.1 \mathrm{M}$ phosphate buffer (PB). Brains were post-fixed in $4 \%$ paraformaldehyde for $24 \mathrm{~h}$ and then stored in $20 \%$ sucrose at $4^{\circ} \mathrm{C}$ until they were sectioned on a cryostat in the coronal plane at a thickness of $40 \mu \mathrm{m}$ and processed for immunohistochemistry (see below). In an effort to reduce variability in staining intensity, tissue sections from all the experimental groups were processed simultaneously within an experiment. 


\subsection{Immunohistochemistry}

In Experiment 1, for the double-labeled $\mathrm{D} \beta \mathrm{H}$ and FOS immunohistochemistry, free-floating hindbrain sections that contained the A2 regions of the NST (corresponding to plates 157-160 of a standard rat atlas (Paxinos and Watson, 2005)) were washed in $0.1 \mathrm{M} \mathrm{PB}$ and incubated for 10 minutes in $0.05 \%$ hydrogen peroxide $\left(\mathrm{H}_{2} \mathrm{O}_{2}\right)$ in $0.1 \mathrm{M}$ phosphate buffered saline (PBS). Sections were then washed in $0.1 \mathrm{M}$ PB with $0.1 \%$ Triton X-100 (PBT), blocked in $2 \%$ normal goat serum (NGS) in PBT for $1 \mathrm{~h}$ at room temperature, and then incubated in rabbit anti-FOS (1:20,000; sc-52; Santa Cruz Biotechnology, Inc., Dallas, TX) in PBT for 24 hours at $4^{\circ} \mathrm{C}$. Sections were then exposed to a secondary antibody (goat anti-rabbit; 1:200, Vector Laboratories, Burlingame, CA) in PBT for 1 hour and then incubated in avidinbiotin horseradish peroxidase complex (1:250; Vectastain ABC Kit, Vector Laboratories) in PBT for 1 hour, both at room temperature. The horseradish peroxidase was visualized with $0.02 \%$ nickel-enhance 3,3 'diaminobenzidine in a $3 \mathrm{M}$ sodium acetate buffer containing $0.05 \% \mathrm{H}_{2} \mathrm{O}_{2}$. Sections were then washed in PBS and then incubated in mouse anti-D $\beta H$ (1:2,000; MAB308; Millipore, Billerica, MA) in PBT for 24 hours at $4^{\circ} \mathrm{C}$. Sections were then exposed to secondary antibody (goat anti-mouse, 1:200) in PBT for 1 hour and then incubated in avidin-biotin horseradish peroxidase complex $(1: 250)$ in PBT for 1 hour, both at room temperature. The horseradish peroxidase was visualized with $0.02 \% 3$ 3, diaminobenzidine (without nickel enhancement) in a $3 \mathrm{M}$ sodium acetate buffer containing $0.05 \% \mathrm{H}_{2} \mathrm{O}_{2}$. Sections were washed in PBS, mounted on to Fisher Brand Plus slides (Fisher Scientific), dried, dehydrated in increasing concentrations of alcohol $(70 \%, 95 \%$, and 
100\%), cleared in xylenes, and coverslipped with DPX Mountant (Sigma-Aldrich, St. Louis, MO).

In Experiment 2, for single-label $\mathrm{D} \beta \mathrm{H}$ immunohistochemistry, free-floating sections containing the PVN (corresponding to plates $47-48$ of a standard rat atlas; Paxinos and Watson, 2005) were washed in $0.1 \mathrm{M} \mathrm{PB}$ and incubated for 10 minutes in $0.05 \% \mathrm{H}_{2} \mathrm{O}_{2}$ PBS. Sections were then washed in $0.1 \mathrm{M} \mathrm{PBT}$, blocked in $2 \% \mathrm{NGS}$ in PBT for 24 hours at $4^{\circ} \mathrm{C}$. Sections were incubated in mouse anti-D $\beta H(1: 2,000$; MAB308; Millipore, Billerica, MA) in PBT for 24 hours at $4^{\circ} \mathrm{C}$. Sections were then exposed to secondary antibody (goat anti-mouse; 1:200) in PBT for 1 hour and then incubated in avidin-biotin horseradish peroxidase complex (1:250) in PBT for 1 hour, both at room temperature. The horseradish peroxidase was visualized with $0.02 \%$ 3,3'diaminobenzidine in a $3 \mathrm{M}$ sodium acetate buffer containing $0.05 \% \mathrm{H}_{2} \mathrm{O}_{2}$. Sections were washed, mounted on to Fisher Brand Plus slides, dried, dehydrated in increasing concentrations of alcohol, cleared in xylenes, and coverslipped with DPX Mountant.

\subsection{Cell Number and Density Quantifications}

The areal densities (cells per unit area) of $\mathrm{D} \beta \mathrm{H}$ - and FOS-positive cell numbers were quantified in the caudal A2 region of the NST. Specifically, only sections from the caudal NST where noradrenergic cells are highly concentrated and non-overlapping with epinephrine-containing cells (approximately Bregma $-15.00 \mathrm{~mm}$ to $-14.50 \mathrm{~mm}$; Paxinos and Watson, 2005)). Two sections, separated by $120 \mu \mathrm{m}$ and anatomically matched across subjects, were used for cell counting. Immunopositive 
cells were counted from images captured with a Zeiss Axiovert 200 microscope under a 20X objective (Carl Zeiss, Thornwood, NY). Using a superimposed grid on each image, bilateral counts were made for each section and averaged to compute the mean number of FOS- and/or D $\beta \mathrm{H}$-positive cells per $15,625 \mu \mathrm{m}^{2}$.

For $\mathrm{D} \beta \mathrm{H}$ immunoreactive densities, two sections containing the PVN, separated by $120 \mu \mathrm{m}$ and anatomically matched across subjects, were analyzed from images captured with a Zeiss Axiovert 200 microscope under a 10X objective. ImageJ was used to measure relative optical densities (RODs) by placing an oval tool over the medial parvocellular area of the PVN (Sawchenko et al., 2000) and subtracting the ROD of the background from an area outside and lateral to the PVN (see Figure 4 for approximately placement of imaging tool). This circumscribed area of the PVN was measured as it has the majority of the noradrenergic input specifically from the A2 region of the NST (Cunningham and Sawchenko, 1988). Bilateral density measures were made for each section and averaged to compute the mean ROD of $\mathrm{D} \beta \mathrm{H}$ staining in the PVN.

\subsection{Statistical Analyses}

All data are presented as the mean \pm standard error of the mean (S.E.M.). Two-way (age $\mathrm{X}$ time point) ANOVAs were used to analyze $\mathrm{D} \beta \mathrm{H}$ - and FOSimmunoreactive single- and double-labeled cells as well as the $\mathrm{D} \beta \mathrm{H}$ immunoreactive RODs in the PVN. Significant main effects and interactions were further analyzed with Tukey's Honestly Significant Difference tests. Differences were considered 
significant when $P<0.05$. All statistical analyses were performed using GraphPad Prism software (version 5.04). 


\section{Acknowledgements}

We would like to thank Page Buchanan for excellent animal care. This work was supported in part from a grant from the National Science Foundation IOS1456577 (to R.D.R.). 


\section{References}

Bundzikova-Osacka, J., Ghosal, S., Packard, B.A., Ulrich-Lai, Y.M., Herman, J.P., 2015. Role of nucleus of the solitary tract noradrenergic neurons in post-stress cardiovascular and hormonal control in male rats. Stress. 18, 221-232.

Busnardo, C., Alves, F.H.F., Crestani, C.C., Scopinho, A.A., Resstel, L.B.M., Correa, F.M.A., 2013. Paraventricular nucleus of the hypothalamus glutamate neurotransmission modulates autonomic, neuroendocrine and behavioral responses to acute restraint stress in rats. European Neuropsychopharmacology. 23, 1611-1622.

Crane, J.W., French, K.R., Buller, K.M., 2005. Patterns of neuronal activiation in the rat brain and spinal cord in response to increasing durations of restraint stress. Stress. 8, 199-211.

Cunningham, E.T., Sawchenko, P.E., 1988. Anatomical specificity of noradrenergic inputs to the paraventricular and supraoptic nuclei of the rat hypothalamus. J. Comp. Neurol. 274, 60-76.

Cunningham, E.T., Bohn, M.C., Sawchenko, P.E., 1990. Ogranization of adrenergic inputs to the paraventricular and supraoptic nuclei of the hypothalamus in the rat. J. Comp. Neurol. 292, 651-667.

Dahl, R.E., Gunnar, M.R., 2009. Heightened stress responsiveness and emotional reactivity during pubertal maturation: implications for psychopathology. Dev. Psychopathol. 21, 1-6.

Dayas, C.V., Buller, K.M., Crane, J.W., Day, T.A., 2001a. Stressor categorization: acute physical and psychological stressors elicit distinctive recruitment patterns in the amygdala and in medullary noradrenergic cell groups. Eur. J. Neurosci. 14, 1143-1152.

Dayas, C.V., Buller, K.M., Day, T.A., 2001b. Medullary neurons regulate hypothalamic corticotropin-releasing factor cell responses to an emotional stressor. Neuroscience. 105, 707-719.

Dayas, C.V., Buller, K.M., Day, T.A., 2004. Hypothalamic paraventricular nucleus neurons regulate medullary catecholamine cell responses to restraint stress. J. Comp. Neurol. 478, $22-34$.

Foilb, A.R., Lui, P., Romeo, R.D., 2011. The transformation of hormonal stress responses throughout puberty and adolescence. J. Endocrinol. 210, 391-398. 
Gaillet, S., Alonso, G., Le Borgne, R., Barnanel, G., Malaval, F., Assenmacher, I., Szafarczyk, A., 1993. Effects of discrete lesions in the ventral noradrenergic ascending bundle on the corticotropic stress response depend on the site of the lesion and on the plasma levels of adrenal steroids. Neuroendocrinology. $58,408-419$.

Goldman, L., Winget, C., Hollingshead, G.W., Levine, S., 1973. Postweaning development of negative feedback in the pituitary-adrenal system of the rat. Neuroendocrinology. 12, 199-211.

Hall, B.S., Romeo, R.D., 2014. The influence of poststress social factors on hormonal reactivity in prepubertal male rats. Dev. Psychobiol. 56, 1061-1069.

Herman, J.P., Figueiredo, H., Mueller, N.K., Ulrich-Lai, Y., Ostander, M.M., Choi, D.C., Cullinan, W.E., 2003. Central mechanisms of stress integration: hierarchical circuitry controlling hypothalamic-pituitary-adrenocortical responsiveness. Front. Neuroendocrinol. 24, 151-180.

Ho, A., Villacis, A.J., Svirsky, S.E., Foilb, A.R., Romeo, R.D., 2012. The pubertalrelated decline in cellular proliferation and neurogenesis in the dentate gyrus of male rats is independent of the pubertal rise in gonadal hormones. Dev. Neurobiol. 72, 743-752.

Hostinar, C.E., Gunnar, M.R., 2013. Future directions in the study of social relationships as regulators of the HPA axis across development. J. Clin. Child Adolesc. Psychol. 42, 564-575.

Kvetnanky, R., Sabban, E.L., Palkovits, M., 2009. Catecholaminergic systems in stress: structural and molecular genetic approaches. Physiol. Rev. 89, 535606.

Lui, P., Padow, V.A., Franco, D., Hall, B.S., Park, B., Klein, Z.A., Romeo, R.D., 2012. Divergent stress-induced neuroendocrine and behavioral responses prior to puberty. Physiol. Behav. 107, 104-111.

Markham, J.A., Morris, J.R., Juraska, J.M., 2007. Neuron number decreases in the rat ventral, but not dorsal, medial prefrontal cortex between adolescence and adulthood. Neuroscience. 144, 961-968.

McCormick, C.M., Mathews, I.Z., 2007. HPA function in adolescence: role of sex hormones in its regulation and the enduring consequences of exposure to stressors. Pharmacol. Biochem. Behav. 86, 220-233. 
McCormick, C.M., Mathews, I.Z., Thomas, C., Waters, P., 2010. Investigations of HPA function and the enduring consequences of stressors in adolescence in animal models. Brain Cogn. 72, 73-85.

Minhas, S., Liu, C., Galdamez, J., So, V.M., Romeo, R.D., 2016. Stress-induced oxytocin release and oxytocin cell number and size in prepubertal and adult male and female rats. Gen. Comp. Endocrinol. 234, 103-109.

Mravec, B., Vargovic, P., Filipcik, P., Novak, M., Kvetnanky, R., 2015. Effect of a single and repeated stress exposure on gene expression of catecholamine biosynthetic enzymes in brainstem catecholaminergic cell groups in rats. Eur. J. Neurosci. 42, 1872-1886.

Paxinos, G., Watson, C., 2005. The rat brain in stereotaxic coordinates., Vol., Elsevier Academic Press, New York.

Pezzone, M.A., Lee, W.-S., Hoffman, G.E., Pezzone, K.M., Rabin, B.S., 1993. Activation of brainstem catecholaminergic neurons by conditioned and unconditioned aversive stimuli as revealed by c-Fos immunoreactivity. Brain Res. 608, 310-318.

Rinaman, L., 2001. Postnatal development of catecholamine inputs to the paraventricular nucleus of the hypothalamus in rats. J. Comp. Neurol. 438, 411-422.

Rinaman, L., 2011. Hindbrain noradrenergic A2 neurons: diverse roles in autonomic, endocrine, cognitive, and behavioral functions. Am. J. Physiol. Regul. Integtr. Comp. Phsyiol. 300, R222-R235.

Romeo, R.D., Lee, S.J., Chhua, N., McPherson, C.R., McEwen, B.S., 2004a. Testosterone cannot activate an adult-like stress response in prepubertal male rats. Neuroendocrinology. 79, 125-132.

Romeo, R.D., Lee, S.J., McEwen, B.S., 2004b. Differential stress reactivity in intact and ovariectomized prepubertal and adult female rats. Neuroendocrinology. 80, 387-393.

Romeo, R.D., Bellani, R., Karatsoreos, I.N., Chhua, N., Vernov, M., Conrad, C.D., McEwen, B.S., 2006a. Stress history and pubertal development interact to shape hypothalamic pituitary adrenal axis plasticity. Endocrinology. 147, 16641674. 
Romeo, R.D., Karatsoreos, I.N., McEwen, B.S., 2006b. Pubertal maturation and time of day differentially affect behavioral and neuroendocrine responses following an acute stressor. Horm. Behav. 50, 463-468.

Romeo, R.D., 2010a. Adolescence: a central event in shaping stress reactivity. Dev. Psychobiol. 52, 244-253.

Romeo, R.D., 2010b. Pubertal maturation and programming of hypothalamicpituitary-adrenal reactivity. Front. Neuroendocrinol. 31, 232-240.

Romeo, R.D., 2013. The teenage brain: the stress response and the adolesent brain. Curr. Dir. Psychol. Sci. 22, 140-145.

Romeo, R.D., Minhas, S., Svirsky, S.E., Hall, B.S., Savenkova, M., Karatsoreos, I.N., 2014. Pubertal shifts in adrenal responsiveness to stress and andrenocorticotropic hormone in male rats. Psychoneuroendocrinology. 42, 146-152.

Romeo, R.D., Patel, R., Pham, L., So, V.M., 2016. Adolescence and the ontogeny of the hormonal stress response in male and female rats and mice. Neurosci. Biobehav. Rev. 70, 206-216.

Rubinow, M.J., Juraska, J.M., 2009. Neuron and glia numbers in the basolateral nucleus of the amygdala from preweaning through old age in male and female rats: a stereological study. J. Comp. Neurol. 512, 717-725.

Sawchenko, P.E., Swanson, L.W., 1981. Central noradrenergic pathways for the integration of hypothalamic neuroendocrine and autonomic responses. Science. 214, 685-687.

Sawchenko, P.E., Swanson, L.W., 1982. The organization of noradrenergic pathways from the brainstem to the paraventricular and supraoptic nuclei in the rat. Brain Res. 257, 275-325.

Sawchenko, P.E., Li, H.-Y., Ericsson, A., 2000. Circuits and mechanisms governing hypothalamic responses to stress: a tale of two paragidms. . Prog. Brain Res. $122,61-78$.

Stornetta, R.L., Sevigny, C.P., Guyenent, P.G., 2002. Vesicular glutamate transporter DNPI/VGLUT2 mRNA is present in C1 and several other groups of brainstem catecholaminergic neurons. J. Comp. Neurol. 444, 191-206.

Ulrich-Lai, Y.M., Herman, J.P., 2009. Neural regulation of endocrine and autonomic stress responses. Nat. Rev. Neurosci. 10, 397-409. 
Vazquez, D.M., Akil, H., 1993. Pituitary-adrenal response to ether vapor in the weanling animal: characterization of the inhibitory effect of glucocorticoids on adrenocorticotropin secretion. Pediatr. Res. 34, 646-653.

Viau, V., Bingham, B., Davis, J., Lee, P., Wong, M., 2005. Gender and puberty interact on the stress-induced activation of parvocellular neurosecretory neurons and corticotropin-releasing hormone messenger ribonucleic acid expression in the rat. Endocrinology. 146, 137-146.

Willing, J., Juraska, J.M., 2015. The timing of neuronal loss across adolescence in the medial prefrontal cortex of male and female rats. Neuroscience. 301, 268275.

Ziegler, D.R., Herman, J.P., 2000. Local intergration of glutamate signaling in the hypothalamic paraventricular region: regulation of glucocorticoid stress responses. Endocrinology. 141, 4801-4804. 


\section{Figure Legends}

Figure 1. Mean ( \pm SEM) number of $D \beta H-(A)$, FOS- $(B)$, and $D \beta H / F O S-(C)$ labeled cells / 15,625 $\mu \mathrm{m}^{2}$ and percent $\mathrm{D} \beta \mathrm{H} /$ FOS-labeled cells (D) in the A2 region of the NST in pre-adolescent (30 days of age) and adult (70 days of age) male rats before (basal), immediately after a 30 min session of restraint stress, or 40 min after the restraint session was terminated. Bars and groups of bars that share a letter are not significantly different from one another.

Figure 2. Representative photomicrograph of $\mathrm{D} \beta \mathrm{H}$ - and FOS-positive cells in the $\mathrm{A} 2$ region of the NST in a pre-adolescent (30 days of age) male 40 min after exposure to a 30 min session of restraint stress $(A)$. Panel $B$ provides a higher magnification imagine of the cells in Panel A (represented by the square box) with white arrows, black arrows, and black arrowheads indicating $\mathrm{D} \beta \mathrm{H}$ single-labeled cells, FOS singlelabeled cells, and $\mathrm{D} \beta \mathrm{H}$ and FOS double-labeled cells, respectively. Scale bar in each panel $=50 \mu \mathrm{m}$.

Figure 3. Mean $( \pm$ SEM) relative optical density $(R O D)$ of $D \beta H$ immunoreactivity in the PVN of pre-adolescent ( 30 days of age) and adult (70 days of age) male rats before (basal), immediately after a 30 min session of restraint stress, or 40 min after the restraint session was terminated. Groups of bars that share a letter are not significantly different from one another. 
Figure 4. Representative photomicrographs of $D \beta H$ immunoreactivity in the PVN in a pre-adolescent (30 days of age) male before (basal; A) or 40 min after exposure to a 30 min session of restraint stress $(B)$. Panels $C$ and $D$ provide a higher magnification of the images in Panels A and B, respectively, with a black and gray oval representing the approximate area of ROD measurement for specific and background signal, respectively. Scale bar for Panels $A$ and $B=200 \mu \mathrm{m}$ and for Panels $C$ and $D=50 \mu \mathrm{m}$. 
Figure 1
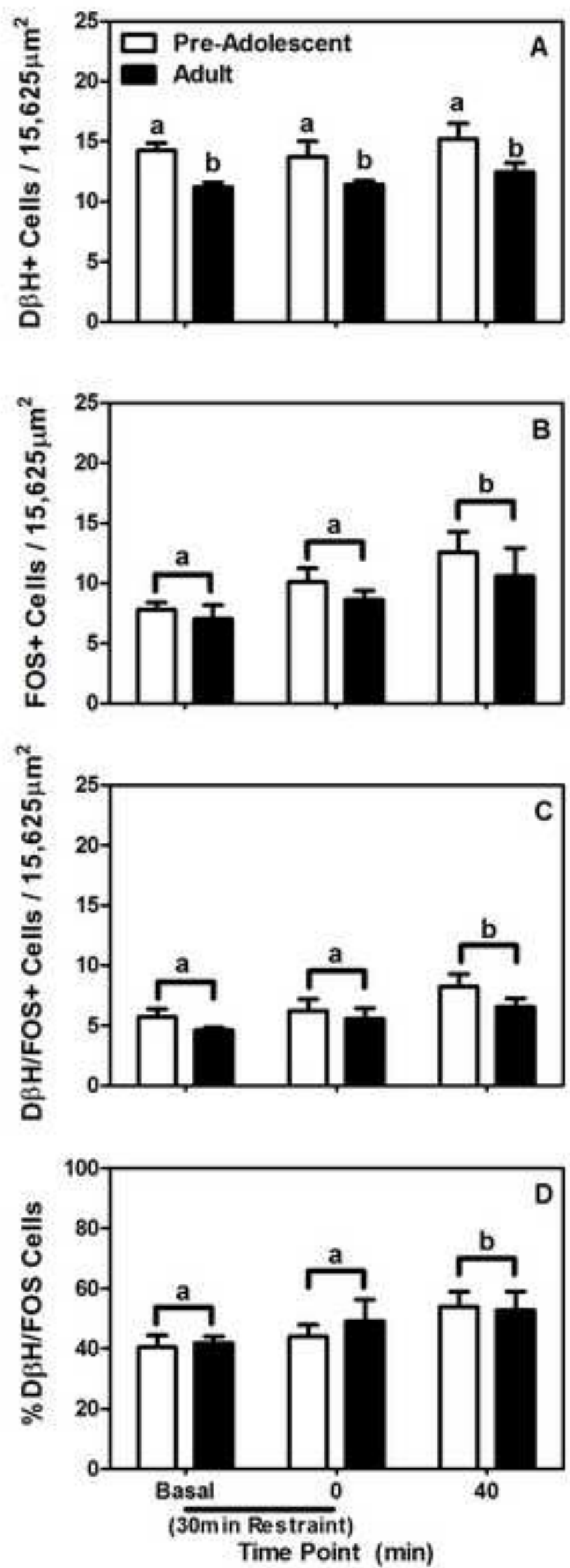


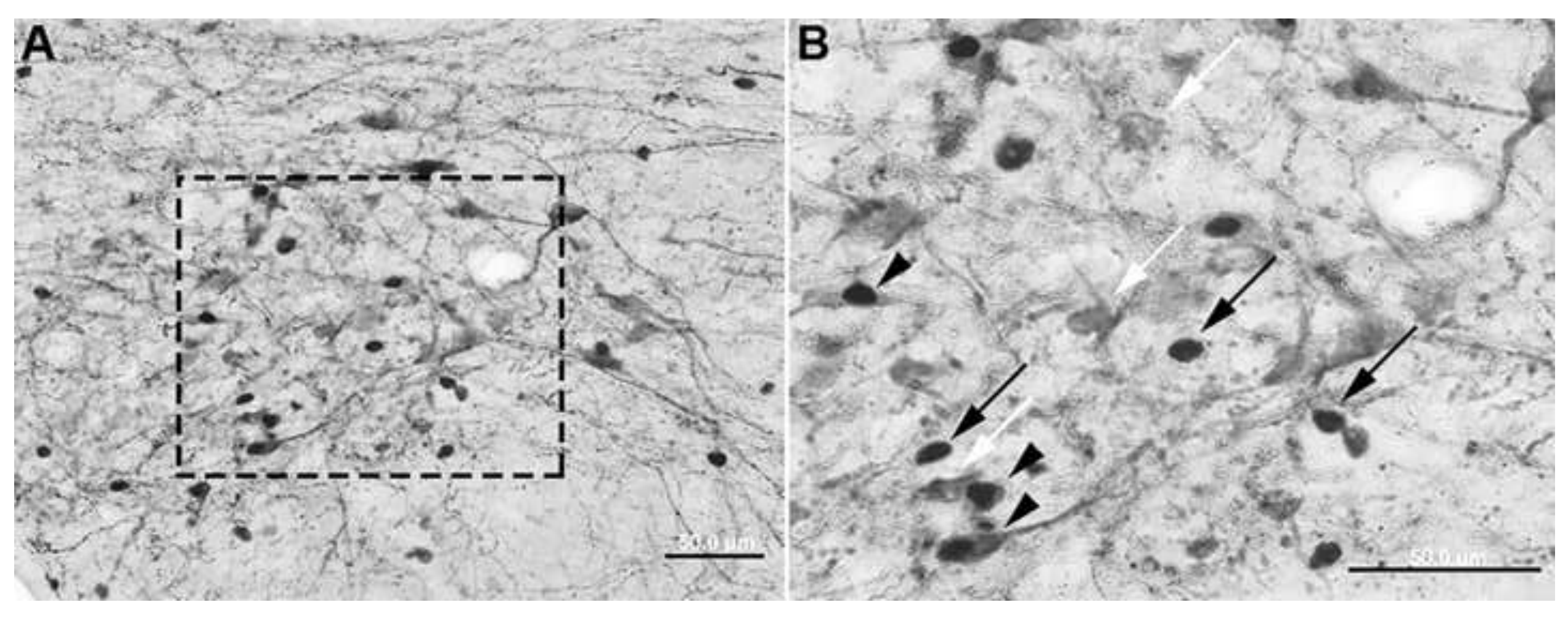
.

.
列

(
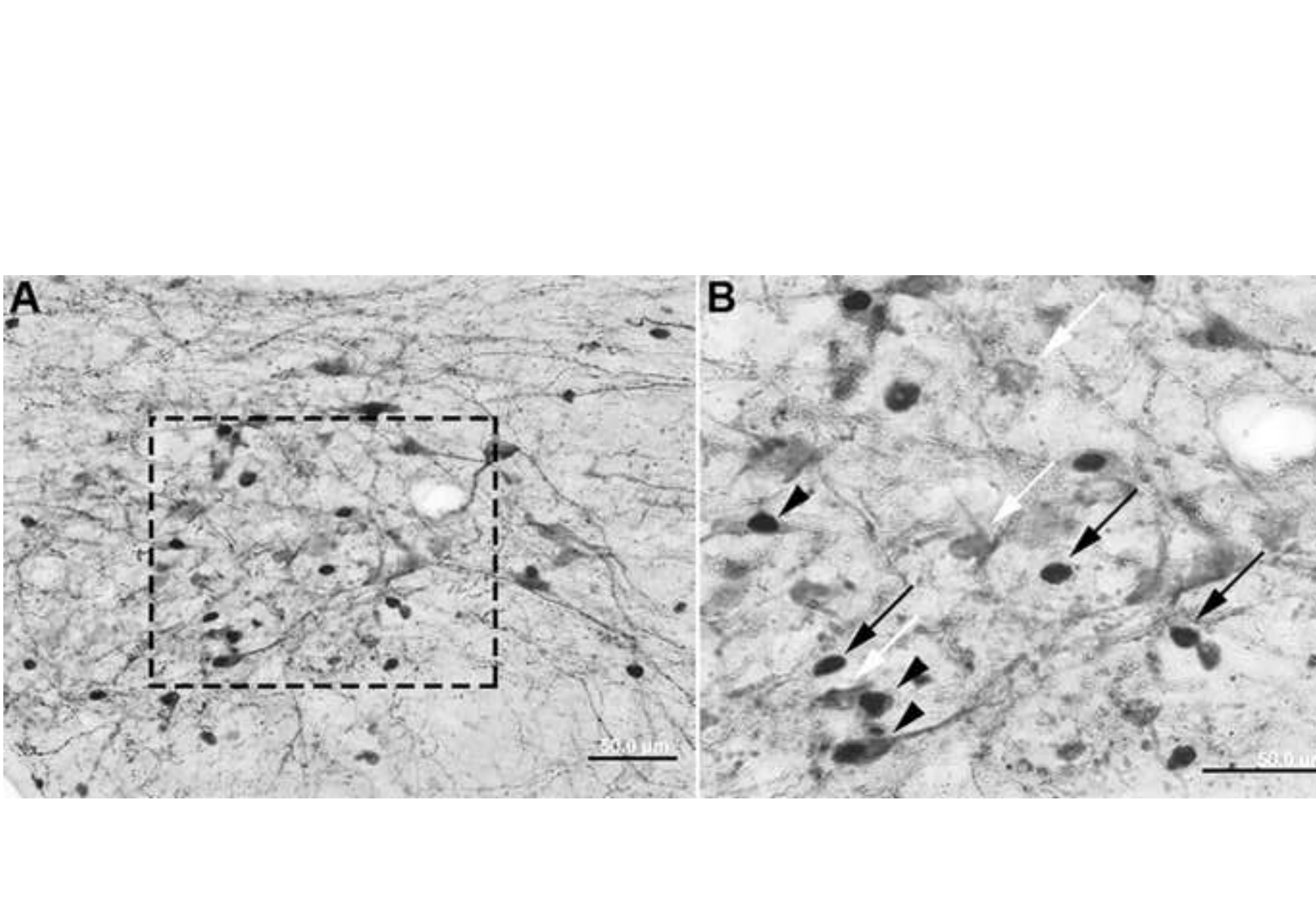

(1)

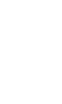




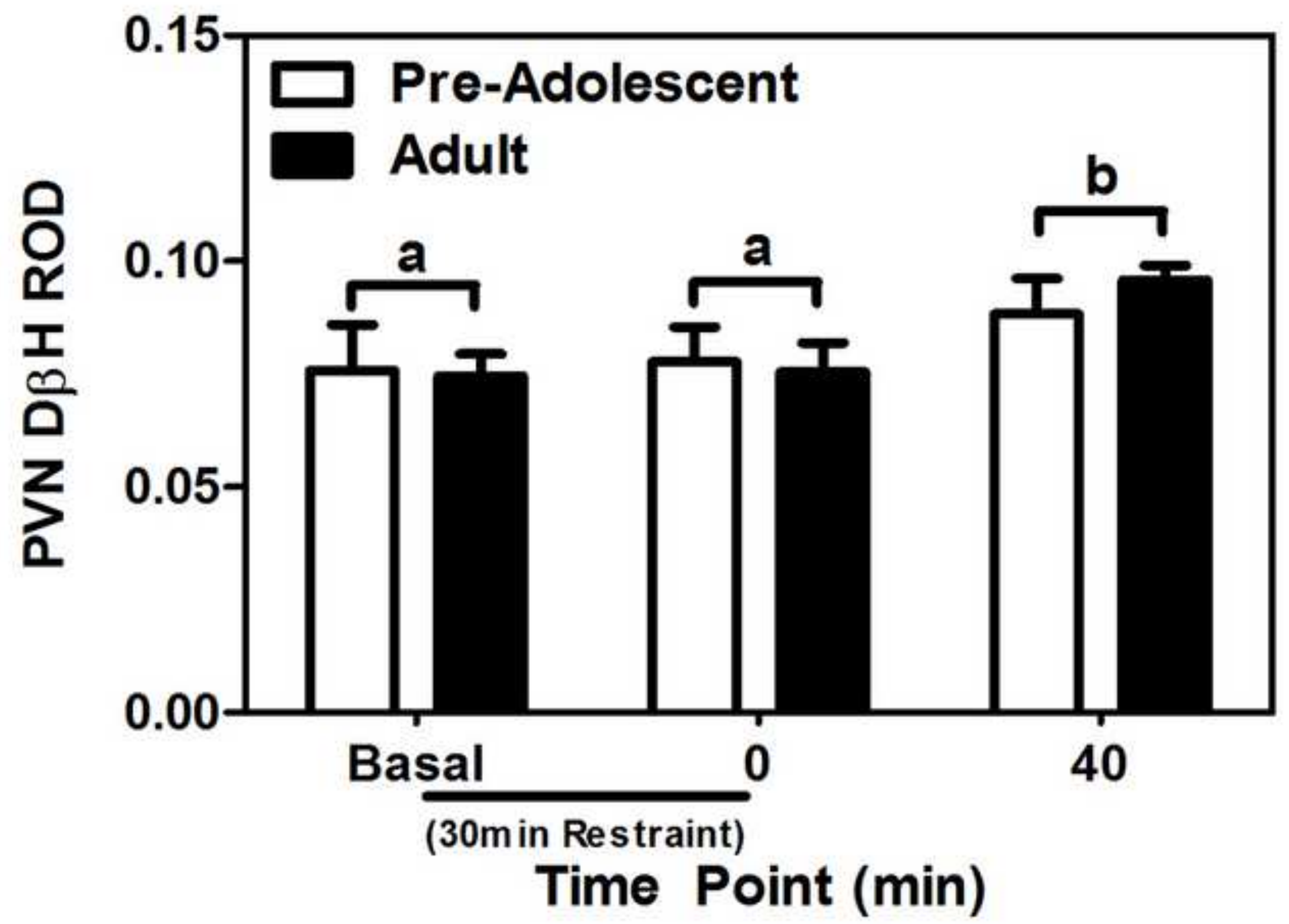


A

C
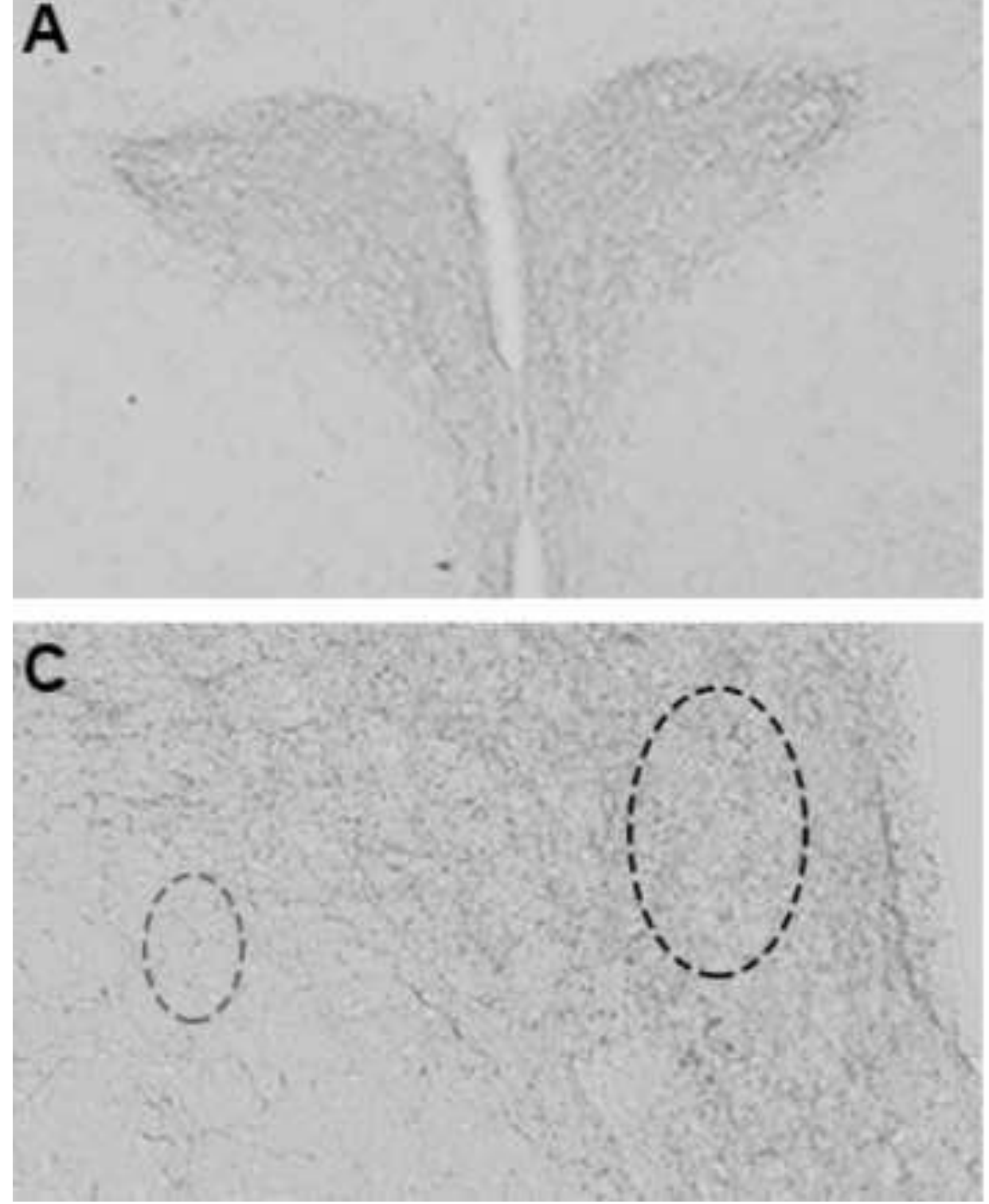

B
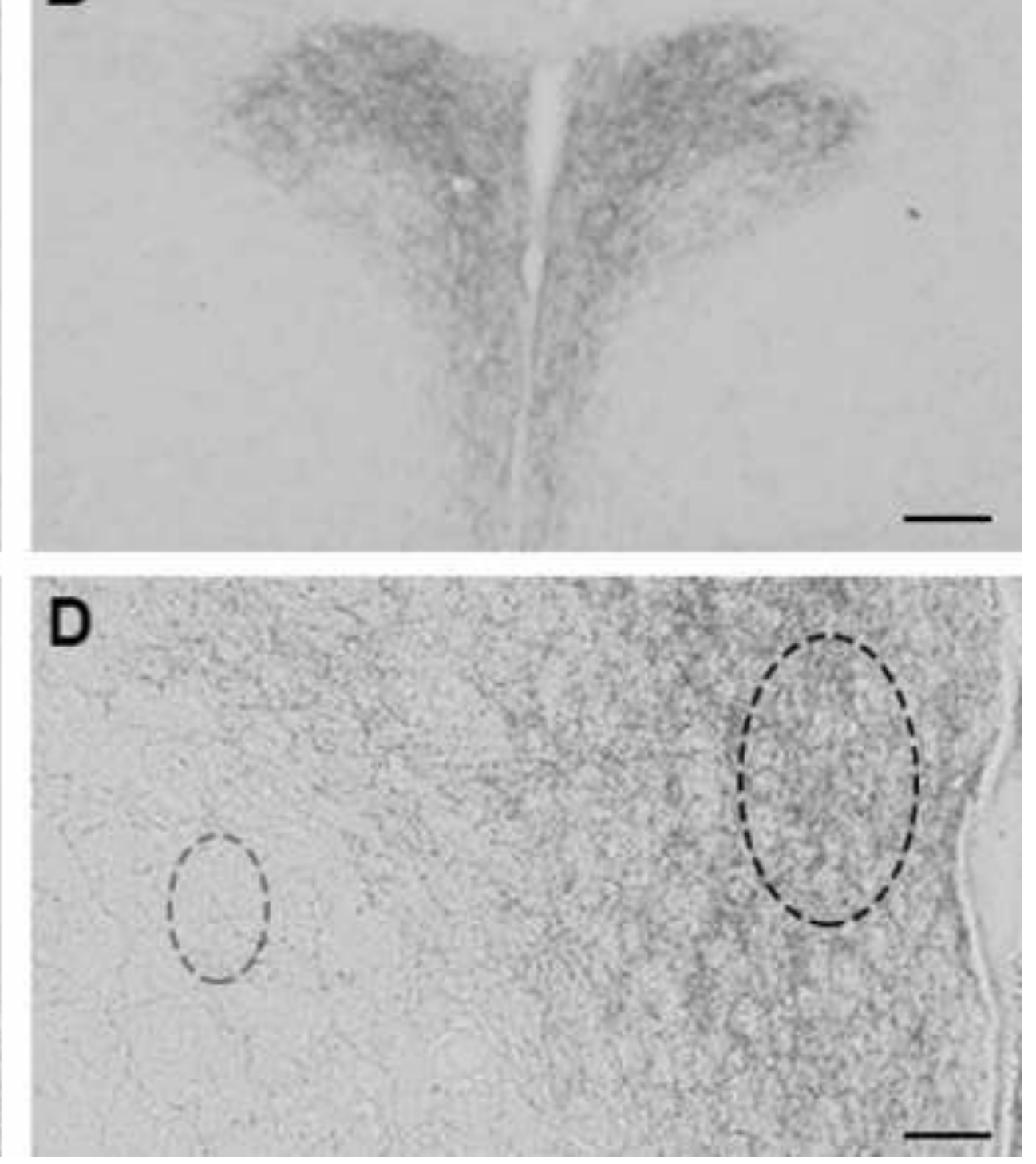